\title{
Effect of variable viscosity on mixed convection boundary layer flow over a vertical surface embedded in a porous medium
}

\begin{abstract}
The steady mixed convection boundary layer flow over a vertical impermeable surface embedded in a porous medium when the viscosity of the fluid varies inversely as a linear function of the temperature is studied. Both cases of assisting and opposing flows are considered. The transformed boundary layer equations are solved numerically by a finite difference method. Numerical results for the flow and heat transfer characteristics are obtained for various values of the mixed convection parameter $\varepsilon$ and the variable viscosity parameter $\theta \mathrm{e}$. It has been found that in the opposing flow case, dual solutions exist and boundary separation occurs.
\end{abstract}

Keyword: Variable viscosity, Mixed convection, Boundary layer, Vertical surface, Porous medium 